\title{
ASSESSMENT OF CHROMOPHORIC DISSOLVED ORGANIC MATTER AND NUTRIENT DISTRIBUTION IN NEW ZEALAND RIVERS USING SATELLITE IMAGES
}

\author{
DADOLAHI, S. A. ${ }^{*}$ MOHAMMAD, A. H. \\ Department of Marine Environment, Faculty of Marine Natural Resources, Khorramshahr \\ University of Marine Science and Technology, Khorramshahr, Iran \\ (phone: +98-913-391-8956; fax: +98-632-423-4405) \\ *Corresponding author \\ e-mail: alidadolahi@gmail.com \\ (Received $2^{\text {nd }}$ Dec 2018; accepted 20 $0^{\text {th }}$ Feb 2019)
}

\begin{abstract}
The importance of chromophoric dissolved organic matter (CDOM) and water parameters for the structure and function of rivers and lake ecosystems has led to the development of a way to estimate the amount of CDOM, TP (total phosphorus) and TN (total nitrogen) in rivers and lakes over large geographic areas. Operational Land Imager (OLI) images have been obtained of the North and South Islands of New Zealand for the March 2014 and 2015, with in-situ measurements of bio-optical properties and the water parameters of 18 stations. Satellite images of the date closest to the water sampling were used to statistically correlate the in-situ measurements with various combinations of Landsat 8 bands in order to develop algorithms that best describe those relationships and calculate accurately the aforementioned water quality components. Optimal models were selected based on statistical criteria and indices; finally, the predictive models of CDOM, TP and TN concentrations involving the combination of ultra-blue (B1), blue (B2) and green (B3) OLI bands of Landsat 8 satellite sensor were achieved. As a result of the validation process, $\mathrm{CDOM}$ absorption at $420 \mathrm{~nm}(\mathrm{R}=0.35)$, TP $(\mathrm{R}=0.57)$ and $\mathrm{TN}$ $(\mathrm{R}=0.71)$ concentrations were shown to be the most accurately estimated components, respectively.
\end{abstract}

Keywords: CDOM, algorithm, TN (total nitrogen), TP (total phosphorus), water quality

\section{Introduction}

Dissolved organic matter (DOM) is the main structuring constituent of aquatic ecosystems. Imported terrestrial dissolved organic matter constitutes a carbon source for heterotrophic bacteria within the aquatic ecosystems, thereby making them partly independent of the primary production of organic substrates within the aquatic ecosystems (Kutser et al., 2005a). Coloured (chromophoric) dissolved organic matter $(\mathrm{CDOM})$ is the part of DOM which absorbs light. According to Slonecker et al. (2016), "CDOM is the humic-rich, optically active fraction of dissolved organic matter that is present in natural waters from the decomposition of detritus and other organic substances". They are also known as chromophoric dissolved organic matter, yellow substance and humic colour (Slonecker et al., 2016; Hoge et al., 1995).

The importance of measuring water quality and CDOM has important implications for drinking water, aquatic ecosystems and element transport (Sloneker et al., 2016; Häder et al., 2007). Generally, there is a strong correlation between the concentrations of DOM and CDOM (Tranvik, 1990) in aquatic ecosystems. The absorption of light by CDOM affects the availability of light for the primary producers (Jones, 1998). For instance, CDOM reduces the light availability in the water column and tends to prevent biological activity, such as photosynthesis, thereby controlling growth in phytoplankton populations, which are essential to aquatic food chains (Slonecker et al., 2016; Häder et al., 2007). 
The CDOM efficiently absorbs short wavelength solar radiation, which effects photochemical reactions, and protects aquatic biota from UV-B induced damage, an effect that is perhaps particularly significant in high latitude waters (Pienitz and Vincent, 2000; Kutser et al., 2005b). The importance of DOM and CDOM to the structure and function of the aquatic ecosystems is a procedure that is necessary to estimate their amounts in freshwater over extensive regions would be highly beneficial. CDOM reflectance happens in the ultraviolet-blue part of the electromagnetic spectrum, but has no unique identifying spectral absorbance or reflectance features. CDOM displays a gently decreasing slope from the ultraviolet through the blue regions (Fig. 1).

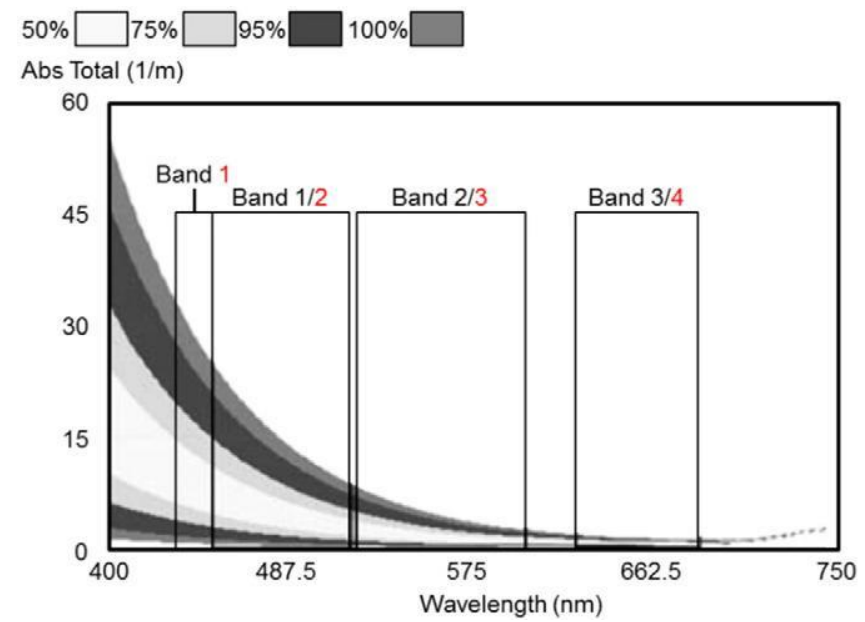

Figure 1. The gradually decreasing absorbance of CDOM in the electromagnetic spectrum and the band location of typical multispectral satellite sensors. Dark numbers represent earlier Landsat sensors and red numbers indicate Landsat 8 bands and the improvement of Band 1 relative to the available energy. The shaded intervals represent typical ranges of 500 simulations (Slonecker et al., 2016)

CDOM is typically derived using absorbance or fluorescence techniques. Spectral absorbance measures how much light at a specific wavelength (typically $254 \mathrm{~nm}$ or 440 $\mathrm{nm}$ ) is absorbed over a range of wavelengths. The main problem in regards to CDOM is that it is neither measured nor reported uniformly. CDOM is sometimes explained as a function of colour at $440 \mathrm{~nm}$ (C440) (Brezonik et al., 2005).

The remote assessment of CDOM helps to get a comprehensive view of the distribution and accessibility of DOM in water and to investigate the response of water DOM concentrations to climate change. Optical remote sensing potentially provides the means to make synoptic measurements of the rivers' and lakes' CDOM over large geographic areas. In summary, remote sensing easily solves the considerable problems of CDOM, since in rivers, CDOM is the dominating absorbing composition with a predictable effect on the reflectance spectrum (high absorption of UV, decreasing exponentially with increasing wavelength) (Kutser et al., 2005a).

A new generation of land observation sensors, such as the Advanced Land Imager (ALI) and Operational Land Imager (OLI), have modified spatial, spectral and radiometric resolution (Kutser et al., 2005a; Slonecker et al., 2016). In practice, such measurements have been limited by main three factors: 
- River and lake size is often small with limited width compared to the most aquatic remote sensing satellite sensors.

- High absorption of CDOM associated with shallow rivers or lakes results in low reflectance and therefore requires satellite measurements of high radiometry sensitivity.

- Limitation in finding suitable images, particularly those areas with high cloud coverage.

The absorption by CDOM decreases with increasing wavelength, thus the influence of CDOM on the remotely sensed signal in OLI band $1(430-450 \mathrm{~nm})$ is stronger than band $2(450-510 \mathrm{~nm})$. Band 1 on Landsat 8 is a new addition to the Landsat suite of bands and could be potentially important to CDOM research as it is relatively narrow and centred in a part of the spectrum that is sensitive to coastal phenomena (Markogianni et al., 2017). Atmospheric correction of the blue wavelength (band 1) always creates a problem, particularly in the case of high turbidity or strongly absorbing waters with inappropriate reflectance, such as in rivers. As such, these cases' sensitivity of blue sensors is often insufficient, especially in cases where blue wavelengths are close to zero in the case of brown, CDOM-rich rivers or lakes. On the other hand, phytoplankton absorption also influences band 1 more than band 2 . Therefore, the ratio band $2 /$ band 3 is more suitable than the band 1/band 3 ratio for CDOM. This is similar to the band 2/band 3 relationship reported by Kutser et al. (2005a) and Slonecker et al. (2016). In addition, the band 2/band 3 relationship on the Landsat 8 OLI sensor shows a potentially important relationship with respect to $a_{\text {CDOM }}$ remote sensing.

Kutser et al. (2005a) and Slonecker et al. (2016) mapped CDOM values and Landsat potential respectively for ALI and OLI water pixels utilising a simple power function (Eq. 1):

$$
\operatorname{aCDOM}(420)=5.20 x^{-276}
$$

where $x$ is the ratio of ALI bands $2(565 \mathrm{~nm})$ and $3(660 \mathrm{~nm})$, and $a_{\mathrm{CDOM}}(420)$ is the absorption coefficient of CDOM at $420 \mathrm{~nm}$. According to Kuster et al. (2005a), there was a strong correlation between in-situ CDOM measurements and the ALI band ratio $\left(\mathrm{R}^{2}=0.83\right)$.

According to Proffitt (2010) investigates on the state of New Zealand's freshwater, pollution and water-related issues as the number one environmental issue facing New Zealand. Many rivers show excessive nutrients, reduced visual clarity due to suspended sediments, and pollution by faecal bacteria. Water quality is appreciably worse at several hundred sites in lowland rivers monitored by regional councils and it was showed among 134 lakes monitored, 56 percent are eutrophic or worse.

The monitoring of water quality is the first step toward understanding the characteristics of water pollution and designing effective mitigation strategies; however, basically water quality parameters (WQPs), such as total nitrogen (TN) and total phosphorus (TP), are obtained by routine monitoring methods (colorimetry) of field sampling and laboratory analyses (Zhang et al., 2018; Song et al., 2012). In addition to cost and labour intensiveness, these traditional approaches are not suitable for monitoring a large number of water bodies at a regional or national scale because of spatial heterogeneity and temporal changes of water quality across aquatic ecosystems. This condition is especially true for urban lake and river systems, where numerous point 
and non-point inputs occur over relatively short distances (Li et al., 2013). With the permanent development of environmental information technology, remote sensing plays an important and effective role in monitoring water quality, because of its large coverage, better efficiency, and lower cost than traditional sampling methods (Liu et al., 2014).

A number of satellite sensors have been applied to the study of surface water quality (Mathews, 2011). Kutser (2012) has recently provided a significant review of remote sensing instruments which can be applied to assess water quality in inland and inshore coastal waters. Although Landsat sensors were not designed for aquatic applications (McCullough et al., 2012), many examples of applications of Landsat images for estimating and/or monitoring inland water quality are founded. Several studies proposed reliable algorithms between Landsat data and water quality parameters, including chlorophyll, phytoplankton concentrations (Brezonik et al., 2005), water quality (Guan et al., 2011), CDOM (Brezonik et al., 2005), blooms of cyanobacteria (Vincent et al., 2004) and total suspended sediments (Zhou et al., 2006).

Few studies have attempted to monitor and model nutrient data, since those data do not have optical properties, and regression models were achieved from statistically insignificant results (Chen and Quan, 2012). Chen and Quan (2012) particularly used Landsat TM imagery to attempt to predict nutrients (nitrogen and phosphorus) concentrations in Tiahu Lake, China with some acceptable results for phosphorus and less successful results for nitrogen. In general, the previous research considerably increases knowledge of water quality, and most of their developed algorithms are commonly based on empirical relationships using classical, simple linear regression models between remotely sensed reflectance values and measurements collected at the same times in the field.

Because CDOM is one of the most important water color parameters and is closely linked to nutrients, some studies have proposed defining the lake trophic state using the nutrient-color paradigm, which includes CDOM absorption (Liu et al., 2014) and this study was one of the first study in this area which has done. Therefore the aims of this study were to explore whether mapping of CDOM is possible for a larger variety of rivers in the case of satellite images collected in variable illumination conditions and the assessment of various water quality parameters (e.g. TP and TN) in the area to develop predictive algorithms for these parameters in order to discuss the potential application of assessing and monitoring the trophic state of the rivers. Finally, developed model and then applied by using operational land imager (OLI)/Landsat- 8 images to show the $a_{\text {CDOM }}$ (440), TP and TN distributions. Selected optimal algorithms were applied to another Landsat 8 images of different dates with available in-situ CDOM, TP and TN absorption data, in order to validate the results.

\section{Methods}

\section{Source of data and dataset reduction}

During this study background information and the data were obtained through this web portal: https://hydrowebportal.niwa.co.nz/, and Larned et al. (2015). We had no control over the quality of data provided to us, but most analytical laboratories have quality assurance programmes in place, and are accredited by International Accreditation New Zealand (the national authority for testing laboratories). 
In the present study, surface water samples were collected for laboratory analysis. The amount of CDOM is demonstrated by the absorption coefficient at wavelength $440 \mathrm{~nm}, a_{\text {СDOM }}(440)$, obtained from spectrophotometric measurements of filtered water (pore size $0.45 \mu \mathrm{m}$ ) in a $4 \mathrm{~cm}$ cuvette, relative to a reference of distilled water (DaviesColley and Vant, 1987; Verburg, 2011). Absorption units were converted to absorption coefficients using the following relationship (Bricaud et al., 1981):

$$
a(\lambda)=2.303 * A(\lambda) / l
$$

where $a(\lambda)=$ absorption coefficient $\left(\mathrm{m}^{-1}\right), A(\lambda)=$ absorbance, and $l=$ cell's light path length $(\mathrm{m})$.

The $a_{C D O M}(420)$ values are calculated from the $a_{C D O M}(440)$ using the common formula of Bricaud et al. (1981):

$$
\operatorname{aCDOM}_{(\lambda)}=\operatorname{aCDOM}(440) \exp [-S(\lambda-440)]
$$

According to Kirk (1994), $S$ varies between 0.01 and $0.02 \mathrm{~nm}$, and even over a wider range according to Kowalczuk (1999). In addition, according to estimations by DaviesColley and Vant (1987), the slope factor $S=0.0187 \mathrm{~nm}^{-1}$ gives the best results for New Zealand freshwater. Based on Kutser et al. (2005a), using the Equation 2 to process the data for a time period of ten days before and after the OLI image acquisition allowed us to drive $a_{\text {СDОм }}(420)$ values from 18 stations (Table 1; Fig. 2) in this research.

Table 1. Bands and geographical coordinates of the sites

\begin{tabular}{c|c|c|c|c|c|c|c}
\hline Site code & Type & Longitude $\left({ }^{\circ} \mathbf{E}\right)$ & Latitude $\left({ }^{\mathbf{}} \mathbf{S}\right)$ & $\mathbf{b}_{\mathbf{1}}$ & $\mathbf{b}_{\mathbf{2}}$ & $\mathbf{b}_{\mathbf{3}}$ & $\mathbf{g}_{\mathbf{4 2 0}}$ \\
\hline RO1 & Baseline & 176.499019 & 38.184519 & 0.0155 & 0.0043 & 0.0041 & 4.360611 \\
RO3 & Impact & 176.697483 & 38.458011 & 0.0315 & 0.0195 & 0.0358 & 8.721223 \\
RO4 & Baseline & 176.746392 & 38.483561 & 0.02 & 0.0076 & 0.0283 & 13.08183 \\
RO5 & Impact & 176.800183 & 38.039678 & 0.022 & 0.0071 & 0.0045 & 2.907074 \\
TU2 & Baseline & 175.814097 & 38.995106 & 0.0101 & 0.0017 & 0.0158 & 18.89598 \\
WA4 & Impact & 175.142414 & 39.786872 & 0.0147 & 0.003 & 0.0059 & 15.98891 \\
WA5 & Baseline & 175.808428 & 39.809578 & 0.0774 & 0.079 & 0.1177 & 20.34952 \\
GS3 & Impact & 177.621308 & 38.199558 & 0.0134 & 0.0006 & 0.0083 & 29.07074 \\
GS4 & Impact & 177.632225 & 37.863189 & 0.1011 & 0.0977 & 0.1134 & 5.814149 \\
HV1 & Baseline & 176.304164 & 39.818406 & 0.0078 & 0.0079 & 0.0134 & 2.907074 \\
HV2 & Impact & 176.926947 & 39.716106 & 0.0346 & 0.0257 & 0.0458 & 11.6283 \\
HV3 & Impact & 176.877156 & 39.594253 & 0.0235 & 0.0136 & 0.027 & 7.267686 \\
HV6 & Baseline & 176.636025 & 39.177683 & 0.0631 & 0.0515 & 0.0734 & 7.267686 \\
GY2 & Impact & 171.297483 & 42.452764 & 0.0125 & 0.0022 & 0.0099 & 26.16367 \\
GY4 & Baseline & 169.299189 & 43.942036 & 0.0412 & 0.0417 & 0.0509 & 1.453537 \\
AX2 & Baseline & 168.864672 & 45.006886 & 0.1204 & 0.1302 & 0.1468 & 1.453537 \\
DN4 & Impact & 169.747208 & 46.236483 & 0.0084 & 0.0065 & 0.0255 & 13.08183 \\
DN8 & Impact & 168.266664 & 46.326156 & 0.0378 & 0.0207 & 0.0311 & 10.17476 \\
\hline
\end{tabular}

RO: Rotorua, TU: Turangi, WA: Wanganui, GS: Gisborne, HV: Havelock North, GY: Greymouth, AX: Alexandra, DN: Dunedin 


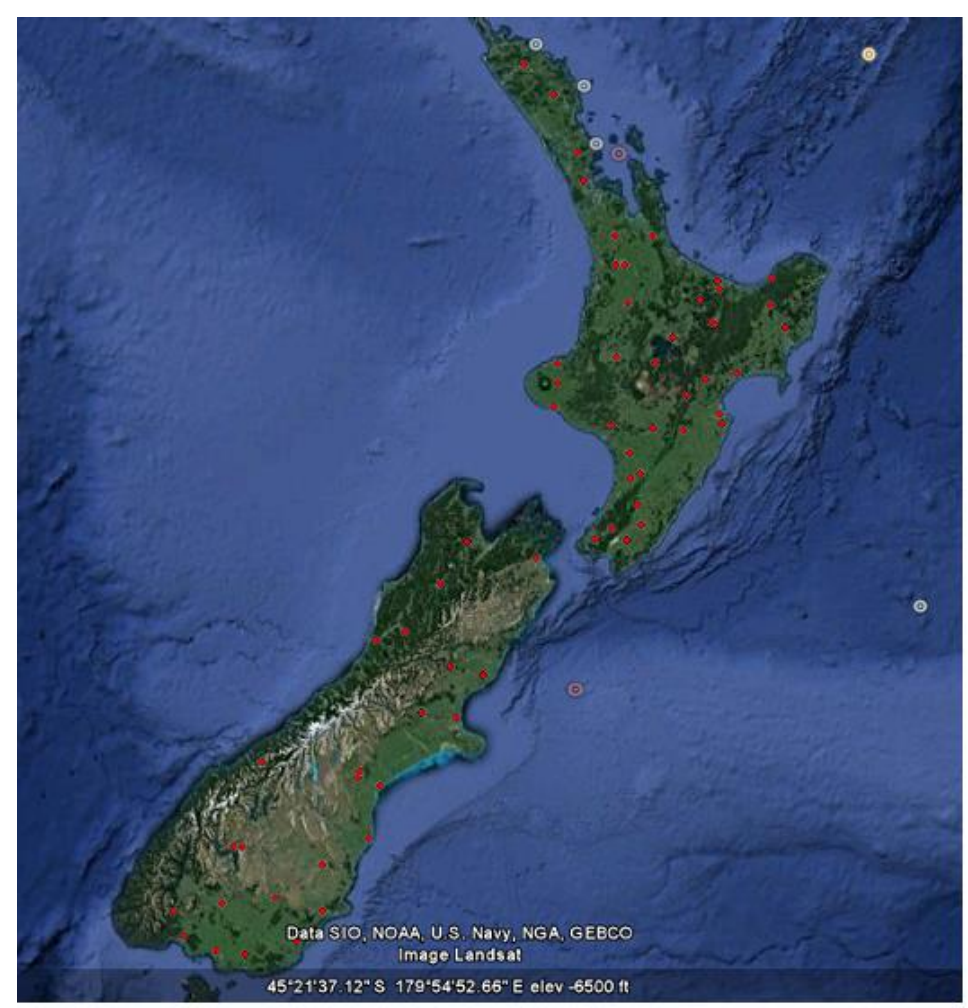

Figure 2. Map showing sampling station from the New Zealand

During present study, satellite images were downloaded from the USGS Hazard Data Distribution System Explorer (http://earthexplorer.usgs.gov) for March 2014 and 2015. Scenes were then atmospherically corrected and processed for CDOM following methods detailed in Kutser et al. (2005a), Griffin et al. (2011) and Slonecker et al. (2016). For this study, and at all stations, the in-situ data were available for nearest dates coinciding with the OLI scenes, therefore making absolute CDOM levels possible to estimate. Unfortunately, relatively limited images were applicable due to the fact that the sky was often cloudy.

Atmospheric correction of satellite measurements is critically important in aquatic remote sensing as a considerable amount (more than $90 \%$ in many cases) of radiation detected by a satellite sensor is backscattered from the atmosphere without ever penetrating the water. Therefore, removing atmospheric effects is especially important when using multiple images.

In this study, and to validate the coloured dissolved organic matter estimation algorithm, and based on two months of field data (2015) and nine OLI images, we used three images from the North and South Islands of New Zealand that were available in the OLI data archive. The rivers in these images are included in the National Institute of Water and Atmospheric Research (NIWA) monitoring programs; thus, water colour determinations are included in these programs and are available.

The water colour measurements enabled us to compute $a_{\mathrm{CDOM}}(420)$, as it was described in the methods section (Eq.3) for comparison with a remote estimate of $a_{\mathrm{CDOM}}(420)$. The estimated values of $a_{\mathrm{CDOM}}(420)$ from the OLI image were correlated with the $a_{\mathrm{CDOM}}(420)$ values calculated from the water colour monitoring data. 
In order to classify the water quality of the areas, the EPA classification system was used (EPA, 2000). Based on this scheme, the classification of water quality in rivers and lakes is according to the TP, TN and trophic index (Trophic State Index-TSI). Based on Zhang et al. (2018), the trophic index TSI is calculated for each classification quality parameter as follows (Eqs. 4-6):

$$
\begin{gathered}
\text { TSI }(\mathrm{TP})=10(9.436+1.624 \ln \mathrm{TP}) \\
\mathrm{TSI}(\mathrm{TN})=10(5.453+1.694 \ln \mathrm{TN}) \\
\mathrm{TSI}=0.219 \mathrm{TSI}(\mathrm{TN})+0.230 \mathrm{TSI}(\mathrm{TP})
\end{gathered}
$$

where TSI (TP) and TSI (TN) were trophic state indexes in relation to TP and TN, respectively; TP and TN were the total phosphorus $(\mathrm{mg} / \mathrm{L}$ and total nitrogen $(\mathrm{mg} / \mathrm{L})$.

\section{Predictive algorithms}

Numerous researchs have investigated one bands, band combinations and band ratios to estimate mainly chl- $a$ and CDOM absorption and to a lesser extent nutrient concentrations in freshwater bodies (Tebbs, et al., 2013; Brezonic, et al., 2015). Firstly, attempts were made to find combinations, transformations, or logarithmic transformations of Landsat 8 OLI bands which would provide more information about the under study parameters in the rivers than only one bond. Such combinations are: ratios of $\mathrm{B} 2 / \mathrm{B} 3, \mathrm{~B} 2 /(\mathrm{B} 1+\mathrm{B} 2+\mathrm{B} 3), \mathrm{B} 1 /(\mathrm{B} 1+\mathrm{B} 2)$. Subsequently, pixel values of each transformed image were retrieved from those regions where the 18 sampling stations are located among all stations (Table 1; Fig. 2).

To develop predictive $a_{\mathrm{CDOM}}(440)$ and nutrients (TN and TP), different regression models and MLR (Multi Liner Regression) relating to in-situ data and reflectance values of the selected bands and band combinations were established. Several regressions resulted in unsuccessful results accompanied by statistically insignificant correlations. Taking into account certain previously mentioned statistical indices, optimal models were recorded for each studied water quality parameter.

\section{Data analysis}

In this study, statistical analysis including the mean values as well as linear and nonlinear fitting, were performed using Statistical Program for Social Sciences (SPSS) 15.0 software. The data from March 2014 were used to establish the relationships and March 2015 data were used to validate between parameters. Distribution maps of rivers and sampling sites were made using ArcGis 11.2 and other data graphs were made using Excel 10 software. In this study, atmospheric correction of the images was performed using the FLAASH (Fast Line-of-sight Atmospheric Analysis of Spectral Hypercubes) software package in ENVI 5.1.

\section{Results}

In this study, it was not possible to use existing data at all stations at exactly the same time as the satellite overpassed. For instance, in both the North and South Islands, field data was gathered from the stations during two weeks, and the satellite overpass took 
place at the end of the first week. Images acquired during fieldwork, particularly in the South Island, were too cloudy for analysis, and that hindered the way first suitable OLI images were acquired ten days before and after the field data were collected. Since, there was not significant differences between the amounts of CDOM in before and after sampling dates so we assumed that the CDOM concentration did not vary dramatically within the time frame that separated the in-situ measurements from the satellite overpasses. Nevertheless, the optical remote sensing make synoptic measurements of inland water CDOM over large geographic regions. In total, measurement of CDOM should be problem that is easily solved by remote sensing.

In this research, the relationship between the $\mathrm{B} 2 / \mathrm{B} 3$ ratio calculated from the atmospherically corrected OLI images and CDOM absorption coefficient at $420 \mathrm{~nm}$ measured is shown in Figure 3. The logarithmic model showed the strongest relationship $\left(\mathrm{R}^{2}=0.65\right)$ and highly significant $(p=0.0001)$ (Fig. 3). From the results of this study, the reflectance modelling results suggest that the B2/B3 ratio is the best for estimating CDOM concentration in rivers as it was suggested by Kutser et al. (2005a) and Slonecker et al. (2016).

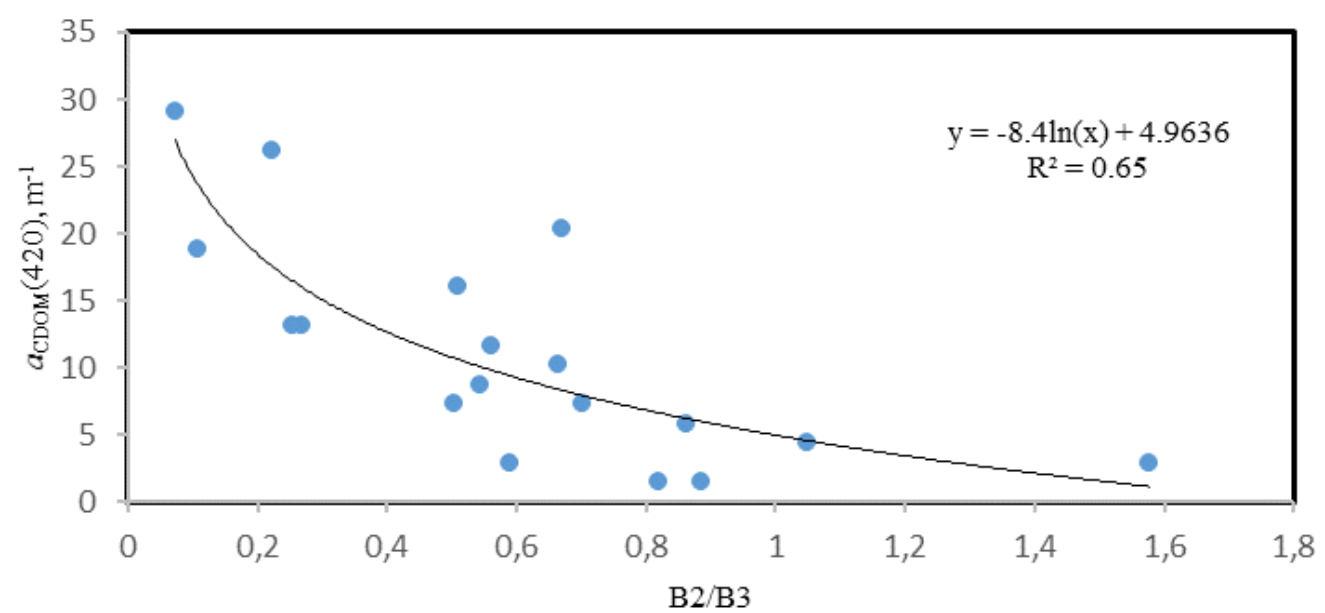

Figure 3. Correlation between OLI band 2 (B2: 520-600 nm) and band 3 (B3: 630-690 nm) ratio calculated from atmospherically corrected OLI images acquired and CDOM absorption coefficient at $420 \mathrm{~nm}$ measured from water samples and the important regression algorithm (logarithmic model)

During present research, the sampling sites covered a wide range of nutrient compositions and trophic states (Table 2). The TN and TP values ranged from 0.019 to $0.719 \mathrm{mg} / \mathrm{L}$ and 0.001 to $0.040 \mathrm{mg} / \mathrm{L}$, respectively. The maximum values of TN, TP and TSI were $0.719,0.040$ and 19.064 and showed about 38,40 and 35 fold greater than the minimum values, respectively. However, the TSI values showed smaller variations from 0.541 to 19.064 , revealing oligotrophic rivers, which are according to the standard trophic categories (Jing et al., 2008): TSI < 30 indicates oligotrophic (Table 3).

During this study, the multi-liner regression model, including the spatial correlation structure and relating it to Landsat 8, bands 1 (ultra-blue), bands 2 (blue) and 3 (green), was shown to be the most appropriate for forecasting CDOM absorption at $420 \mathrm{~nm}$ and total phosphorus built on the logarithmic models. The correlation coefficient is equivalent to 0.81 , while the Durbin-Watson value shows independence of residuals to CDOM (Table 4). 
Table 2. Descriptive statistics of the CDOM, total nitrogen (TN), total phosphorus (TP) and trophic state index (TSI)

\begin{tabular}{c|c|c|c|c}
\hline & $\boldsymbol{a}(\mathbf{4 4 0})\left(\mathbf{m}^{-\mathbf{1}}\right)$ & $\mathbf{T N}(\mathbf{m g} / \mathbf{L})$ & $\mathbf{T P}(\mathbf{m g} / \mathbf{L})$ & TSI \\
\hline Min & 0.020 & 0.019 & 0.001 & 0.541 \\
Max & 2.820 & 0.719 & 0.040 & 19.064 \\
Mean & 0.488 & 0.191 & 0.016 & 10.052 \\
Standard deviation & 0.648 & 0.198 & 0.012 & 5.438 \\
Median & 0.305 & 0.121 & 0.010 & 11.290 \\
\hline
\end{tabular}

Table 3. Trophic state classification based on the estimated TSI

\begin{tabular}{c|c|c|c|c|c}
\hline & Oligotrophic & Mesotrophic & \multicolumn{3}{|c}{ Eutrophic } \\
\hline \multirow{3}{*}{ TSI } & \multirow{3}{*}{ TSI $<30$} & $30 \leq \mathrm{TSI} \leq 50$ & \multicolumn{3}{|c}{ TSI $>50$} \\
\cline { 4 - 6 } & & & $\begin{array}{c}\text { Light eutrophic } \\
50<\mathrm{TSI} \leq 60\end{array}$ & $\begin{array}{c}\text { Moderate eutrophic } \\
60<\mathrm{TSI} \leq 70\end{array}$ & $\begin{array}{c}\text { Hyper eutrophic } \\
\text { TSI }>70\end{array}$ \\
\hline This study & \multicolumn{3}{c}{ TSI $=10$ (strictly oligotrophic) } \\
\hline
\end{tabular}

Table 4. Water quality parameters and best predictive models summary

\begin{tabular}{c|c|c|c|c|c}
\hline Model & $\mathbf{R}$ & $\mathbf{R}^{2}$ & $\begin{array}{c}\text { Std. error of } \\
\text { the estimate }\end{array}$ & $\begin{array}{c}\text { Adjusted R } \\
\text { square }\end{array}$ & Durbin-Watson \\
\hline$a_{\text {CDOM420 }=-8.4 \mathrm{Ln}[\mathrm{B} 2 / \mathrm{B} 3]+4.964}$ & 0.81 & 0.65 & 5.04 & 0.63 & 1.637 \\
$\mathrm{TP}=-0.01 \mathrm{Ln}[\mathrm{B} 2 /(\mathrm{B} 1+\mathrm{B} 2+\mathrm{B} 3)]-0.001$ & 0.53 & 0.29 & 0.01 & 0.24 & 1.393 \\
$\mathrm{TN}=0.209 *[\mathrm{~B} 1 / \mathrm{B} 1+\mathrm{B} 2)]^{1.308}$ & 0.28 & 0.08 & 1.04 & 0.02 & 2.037 \\
\hline
\end{tabular}

In the present work, the ideal model for calculating the total phosphorus was confirmed to be the one established on the logarithmic model. While the amount of the correlation coefficient is equivalent to 0.53 , the Durbin-Watson value of 1.393 for TP indicates independence of the residual value as well. The best estimating model of total nitrogen concentrations involves band 1 (ultra-blue) and 2 (blue), which is the power model, while the correlation coefficient is 0.28 .

To investigate the consistency of the final predictive models, regression between Landsat 8-estimates of the aCDOM (420), total phosphorus and total nitrogen in the stations versus corresponding in-situ data from 2014 were determined (Fig. 4). Several models (linear, logarithmic, quadratic, cubic, power and exponential) have been utilised to discover the best possible concurrence between the monitored and satellite approximated values with the cubic model showing the highest correlation coefficients for all parameters (Table 5). However, the reasonable fit between in-situ and anticipated water quality parameters by each particular MLR showed these models to have adequate and low predictive power, especially the topmost correlation coefficient regarding the aсDOM 420 estimation was 0.35 with a standard error of $0.665 \mathrm{~m}^{-1}$. The resulting correlation coefficients of total phosphorus and total nitrogen concentrations were determined to be 0.57 and 0.71 with standard errors of 0.017 and $0.037 \mathrm{mg} / \mathrm{l}$, respectively. 


$$
\text { - } 3584 \text { - }
$$
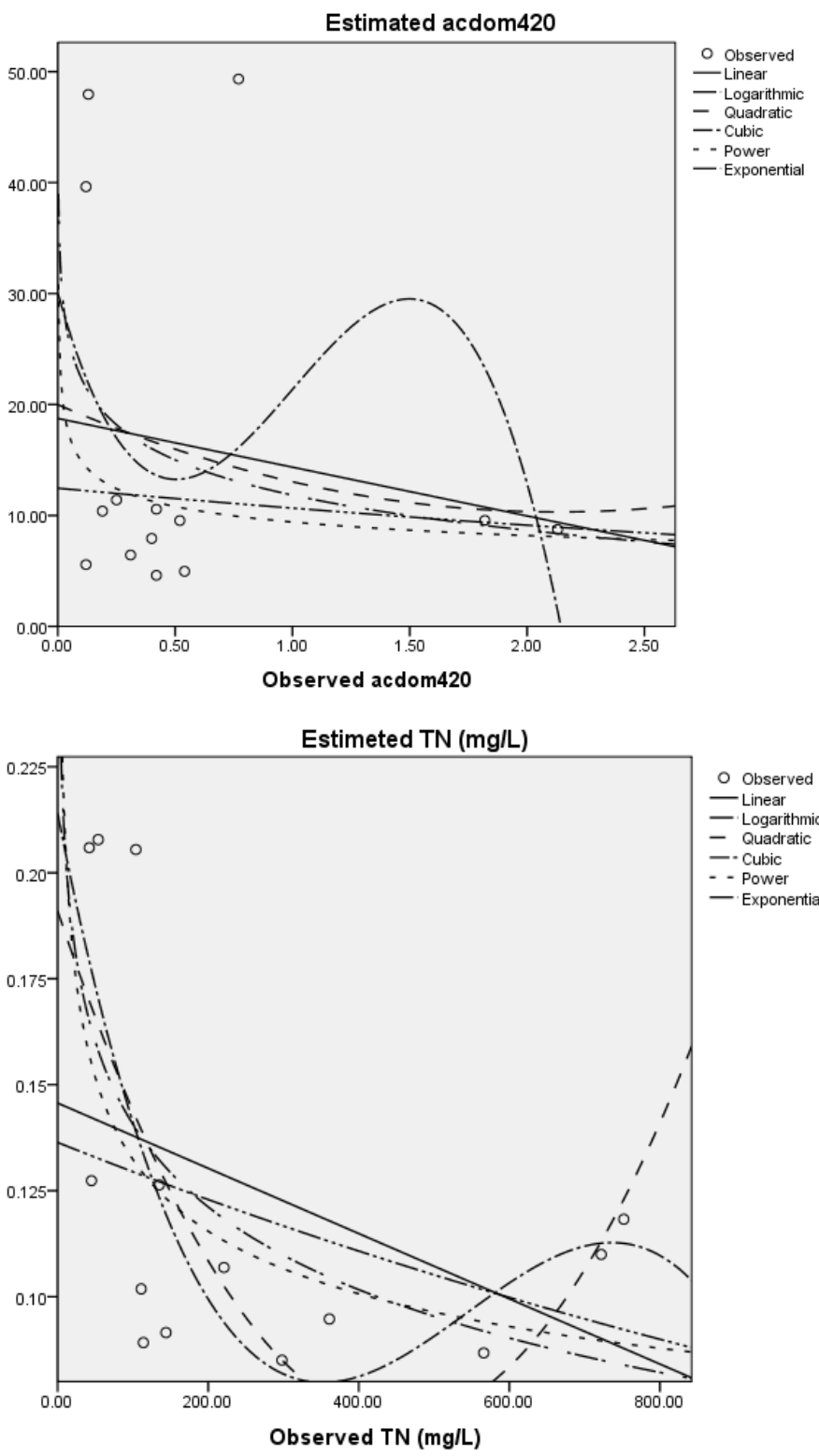

○ observed 二-Linear - Quadratic -- Cubic

- Exponential

Estimated TP (mg/L)

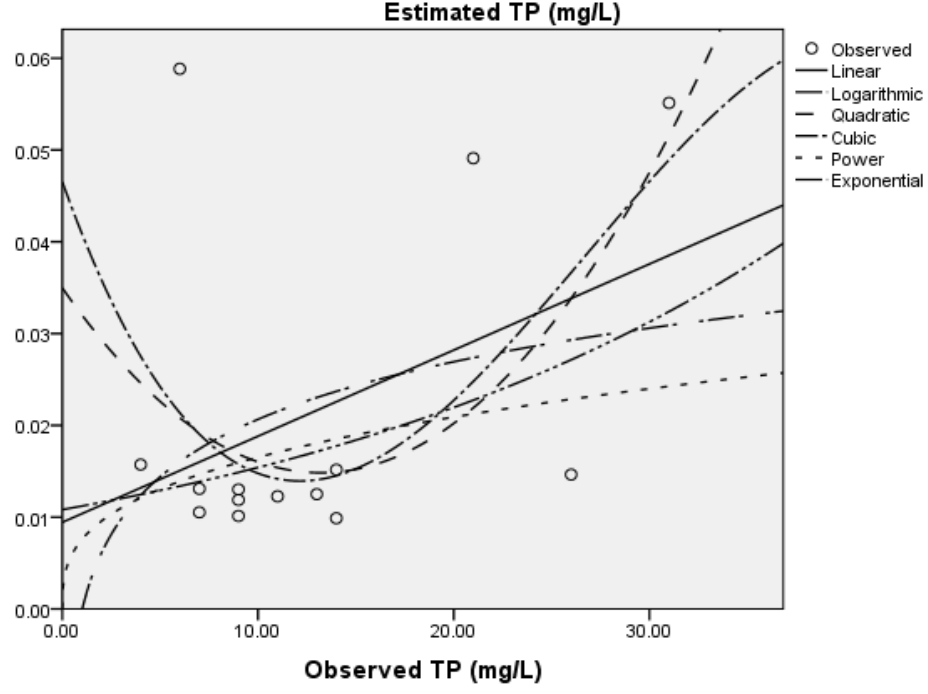

Figure 4. Scatterplots among observed and satellite-derived data

APPLIED ECOLOGY AND ENVIRONMENTAL RESEARCH 17(2):3575-3589.

http://www.aloki.hu • ISSN 15891623 (Print) • ISSN 17850037 (Online)

DOI: http://dx.doi.org/10.15666/aeer/1702_35753589

(c) 2019, ALÖKI Kft., Budapest, Hungary 


$$
-3585-
$$

Table 5. Models summery for water quality parameters predictive models validation

\begin{tabular}{c|c|c|c|c}
\hline acDom420 & $\mathbf{R}$ & $\mathbf{R}^{\mathbf{2}}$ & Adjusted R square & Std. error of the estimate \\
\hline Linear & 0.168 & 0.028 & -0.053 & 0.638 \\
Logarithmic & 0.255 & 0.015 & -0.068 & 0.642 \\
Quadratic & 0.172 & 0.030 & -0.147 & 0.666 \\
Cubic & 0.347 & 0.120 & -0.144 & 0.665 \\
Power & 0.225 & 0.051 & -0.028 & 0.815 \\
Exponential & 0.121 & 0.015 & -0.068 & 0.830 \\
\hline Total phosphorus & & & & 0.017 \\
\hline Linear & 0.413 & 0.171 & 0.101 & 0.018 \\
Logarithmic & 0.289 & 0.084 & 0.007 & 0.016 \\
Quadratic & 0.558 & 0.312 & 0.187 & 0.017 \\
Cubic & 0.566 & 0.321 & 0.117 & 0.636 \\
Power & 0.304 & 0.092 & 0.017 & 0.601 \\
Exponential & 0.436 & 0.190 & 0.123 & 0.043 \\
\hline Total nitrogenous & & & & 0.038 \\
\hline Linear & 0.415 & 0.172 & 0.103 & 0.036 \\
Logarithmic & 0.599 & 0.359 & 0.305 & 0.037 \\
Quadratic & 0.688 & 0.473 & 0.377 & 0.273 \\
Cubic & 0.713 & 0.509 & 0.361 & 0.311 \\
Power & 0.592 & 0.350 & 0.296 & 0.086 \\
Exponential & 0.395 & 0.156 & &
\end{tabular}

\section{Discussion}

Remote sensing offers appropriate data regarding water quality and aquatic systems management. During this study, we demonstrated the applicability probability of Landsat 8 OLI imagery combined with in-situ water parameter concentrations to distinguish applicable algorithms for water quality representation in an oligotrophic water body, New Zealand's rivers. Water specimens from these rivers were evaluated in March 2014 concerning the concentrations of total nitrogen, total phosphorus and CDOM concentration, which then was established as absorption at $440 \mathrm{~nm}, a_{\mathrm{CDOM}(440) \text {, }}$ inferred from the absorption spectra.

Multiple linear regressions were conducted among available data, and insignificant statistical correlations characterised the majority of models. Optimal models were selected based on statistical criteria and indices but they presented low coefficients and unsuccessful results. The selected predictive models of TN, TP and CDOM concentrations involved the combination of ultra-blue (B1), blue (B2) and green (B3) OLI bands of Landsat 8 satellite sensor. These results are in accordance with those of Pahlevan et al. (2014) and Markogianni et al. (2017).

Pahlevan et al. (2014) found out that in waters with relatively low CDOM concentrations $\left(a_{\operatorname{CDOM}(440)}<0.5 \mathrm{~m}^{-1}\right)$, the blue and green bands exhibit the highest sensitivity, whereas the red band was found insensitive to the changes in CDOM absorption. In general, it was found that the OLI is, on average, sensitive to changes in CDOM absorption larger than $0.1 \mathrm{~m}^{-1}$. Although actual retrievals can be improved by the use of multiple bands, in our case detected changes to a lesser extent in CDOM absorption are slightly equal to the aforesaid threshold values which could be the main 
reason for lack of precision assessment results. Furthermore, Pahlevan and Schott (2013) used a physics-based approach to fully examine the potential of OLI in terms of its enhanced features in a water constituent retrieval framework. Based on the results of Pahlavan and Schott (2013), it was concluded that the disparity between the response functions of OLI is more noticeable in turbid waters than in clearer waters when mapping CDOM absorption. Development of reliable methods to retrieve CDOM information from spectral reflectance data is difficult. Indeed, among the major water quality variables measurable by remote sensing (e.g. suspended solids, chlorophyll, Secchi depth), for many reasons, CDOM may be the most difficult to measure accurately in inland waters. CDOM absorbs but does not scatter or reflect light while it has no absorbance peaks, such as those found in plant pigments; instead, light absorption by CDOM follows a simple quasi-exponential decrease with increasing wavelength. There are no wavelength bands in the visible spectrum unlikely associated with CDOM that can be used for measurement purposes. Thus, measurement of low to moderate levels of CDOM in optically complex Case- 2 waters is particularly difficult because light scattering by these particles dominates their reflectance spectra (Markogianni et al., 2017).

Predicting the concentration of total nitrogen and phosphorus in inland waters can be a hard task since very few studies have attempted to monitor data with non-optical properties, such as nutrient concentrations. Furthermore, not many previous studies have been able to provide total nitrogen and phosphorus models with statistically significant results or reasonable adjusted $\mathrm{R}^{2}$ values (Isenstein and Park, 2014). Our research resulted in the total nitrogenous predictive model incorporating ultra-blue, and blue bands yielding a regression coefficient equal to 0.71 , regarding the validation process. Similar results, regarding the utilised wavelengths, presented by Dewidar and Khedr (2001) and Isenstein and Park (2014), who detected the strongest correlation among total nitrogen and phosphorus with Landsat TM bands 1 (blue), 2 (green). Meanwhile the latest researchers have predicted total nitrogen concentrations with Landsat TM bands 1 (blue), 2 (green), 3 (red), and 4 (NIR), although all of these results were not very successful $\left(\mathrm{R}^{2}=0.24\right)$.

The outcome of this study initiates new perceptions in limnology over various scales. For instance, it is conceivable to investigate the unpredictability and dynamics of CDOM concentrations in a limited area, such as lakes, rivers and estuaries. This research revealed that the spatial variability of CDOM concentrations within bigger lakes or rivers could be substantial since those wider and deeper sites showed acceptable results by comparing the results of in situ with the satellite images. A single OLI image comprises a wide area and permits research into river and lake CDOM distribution on a regional scale. The results of this study showed that more measurement accuracy was particularly impeded from the very low concentrations which effectively describe rivers and the absence of any value differentiation among the specimen locations. However, some model predictions applied to oligotrophic water bodies are not so exact (McCullough et al., 2012), and the models resulting from this research increase understanding of water quality deterioration.

\section{Conclusion}

This paper was intended to provide a framework that would lead to method of mapping CDOM for New Zealand inland waters using satellite images and open a 
discussion about the possibility of developing an algorithm to assess and monitor rivers water quality.

The results of this study showed that extremely low concentrations and inland waters are significant factors that hiders the assessment accuracy which strongly characterize inland waters of any value differentiation among the sampling stations. Although, different models predictions applied to oligotrophic lakes are less accurate and normally these models increase knowledge of their water quality and can be useful indicators of water deterioration.

From the results of this study, it is recommended that future work is still needed to establish the fundamental equations linking the remotely sensed data to the in-situ measurements. The specific research considerations include:

1. More direct considerations between in-situ sensors and Landsat 8 overpasses, especially for lakes and estuaries.

2. More corrections for Landsat 8 surface reflectance product, since there is still a high degree of variability in Landsat 8 reflectance values that could potentially be adjusted by additional spectral and atmospheric corrections.

3. Comparative research of CDOM in lakes, rivers, estuaries and coastal environments are needed to understand significant differences, especially in terms of remote sensing capabilities.

Acknowledgements. Special thanks to NIWA (National Institute of Water and Atmospheric) for providing the data, my Supervisor Dr. Luitgard Schwendenmann in University of Auckland to her guidance during my sabbatical for generous help, particularly in data analysis.

\section{REFERENCES}

[1] Brezonik, P., Menken, K. D., Bauer, M. (2005): Landsat-based remote sensing of lake water quality characteristics, including chlorophyll and colored dissolved organic matter (CDOM). - Lake and Reservoir Management 21(4): 373-382.

[2] Bricaud, A., Morel, A., Prieur, L. (1981): Absorption by dissolved organic matter of the sea (yellow substance) in the UV and visible domains. - Limnology and Oceanography 26: 43-53.

[3] Chen, J., Quan, W. T. (2012): Using Landsat/TM imagery to estimate nitrogen and phosphorus concentration in Taihu Lake, China. - IEEE J-STARS 5: 1 273-280.

[4] Davies-Colley, R. J., Vant, W. N. (1987): Absorption of light by yellow substance in freshwater lakes. - Limnology and Oceanogrphy 32(2): 416-425.

[5] Dewidar, K., Khedr, A. (2001): Water quality assessment with simultaneous Lansat-5 TM at Manzala Lagoon Egypt. - Hydrobiologia 457(1-3): 49-58.

[6] EPA (2000): Nutrient Criteria, Technical Guidance Manual. Lakes and Reservoirs. $1^{\text {st }}$ Ed. - EPA-822-B00-001. US Environmental Protection Agency, Washington, DC.

[7] Griffin, C. G., Frey, K. E., Rogan, J., Holmes, R. M. (2011): Spatial and interannual variability of dissolved organic matter in the Kolyma River, East Siberia, observed using satellite imagery. - Journal of Geophysical Research: Biogeosciences 116: G03018 165176.

[8] Guan, X., Li, J., Booty, W. G. (2001): Monitoring lake Simcoe water clarity using Landsat-5 TM images. - Water Resource Management 25(8): 2015-2033.

[9] Häder, D.-P., Kumar, H., Smith, R., Worrest, R. (2007): Effects of solar UV radiation on aquatic ecosystems and interactions with climate change. - Photochemical and Photobiological Sciences 6: 267-285. 
[10] Hoge, F. E., Vodacek, A., Swift, R. N., Yungel, J. K., Blough, N. V. (1995): Inherent optical properties of the ocean: retrieval of the absorption coefficient of chromophric dissolved organic matter from airborne laser spectral fluorescence measurements. Applied Optics 34(30): 7032-7038.

[11] Jones, R. I. (1998): Phytoplankton, Primary Production and Nutrient Cycling. - In: Hessen, D., Tranvik, L. (eds.) Aquatic Humic Substances: Ecology and Biogeochemistry. Springer Verlag, Berlin.

[12] Jing, H., Hua, L., Guo, J. (2008): Analysis on urban lakes eutrophication status in Beijing. - Journal of Lake Sciences 20(3): 357-263.

[13] Isenstein, E. M., Park, M.-H. (2014): Assessment of nutrient distribution in Lake Champlain using satellite remote sensing. - Journal of Environment Sciences 26: 18311836.

[14] Kirk, J. T. O. (1994): Light and Photosynthesis in Aquatic Ecosystems Melbourne. Cambridge University Press, Cambridge.

[15] Kowalczuk, P. (1999): Seasonal variability of yellow substance absorption in the surface layer of the Baltic Sea. - Journal of Geophysical Research 104(C12): 30047-30058.

[16] Kutser, T. (2012): The possibility of using the Landsat image archive for monitoring long time trends in coloured dissolved organic matter concentration in lake waters. - Remote Sensing of the Environment 123: 334-338.

[17] Kutser, T., Pierson, D. C., Kallio, K. Y., Reinart, A., Sobek, S. (2005a): Mapping lake CDOM by satellite remote sensing. - Remote Sensing of the Environment 94: 535-540.

[18] Kutser, T., Pierson, D. C., Tranvik, L., Reinart, A., Sobek, S., Kallio, K. (2005b): Using satellite remote sensing to estimate the colored dissolved organic matter absorption coefficient in lakes. - Ecosystems 8: 709-720.

[19] Larned, S., Snelder, T., Unwin, M., McBride, G., Verburg, P., McMillan, H. (2015): Analysis of water quality in New Zealand lakes and rivers: data sources, data sets, assumptions, limitations, methods and results. - NIWA Client Report no. CHC2015-033. data.mfe.govt.nz/x/DDui3u from the Ministry for the Environment Data Service.

[20] Li, J., Liu, H. X., Li, Y. C., Mei, K. (2013): Dahlgren, R.; Zhang, M. H. Monitoring and modeling dissolved oxygen dynamics through continuous longitudinal sampling: A case study in Wen-Rui Tang River, Wenzhou, China. - Hydrobiological Process 27: 35023510 .

[21] Liu, X., Zhang, Y., Shi, K., Zhu, G., Xu, H., Zhu, M. (2014): Absorption and fluorescence properties of chreomophoric dissolved organic matter: implications for the monitoring of water quality in a large subtropical reservoir. - Environmental Science Pollution Research 21(24): 14078-14090.

[22] Mathews, M. W. (2011): A current review of empirical procedures of remote sensing in inland and near-coastal transitional waters. - International Journal of Remote Sensing 32(21): 6855-6899.

[23] Markogianni, V., Kalivas, D., Petropoulos, G., Dimitrio, E. (2017): Analysis on the feasibility of Landsat 8 imagery for water quality parameters assessment in an oligotrophic Mediterranean lake. - ICGRS 2017, 19th International Conference on Geoscience and Remote Sensing , Rome, Italy.

[24] McCullough, I. M., Loftin, C. S., Sader, S. A. (2012): Combining lake and watershed characteristics with Landsat TM data for remote estimation of regional lake clarity. Remote Sensing Environmental Journal 123: 109-115.

[25] Pahlavan, N., Schott, R. J. (2013): Leveraging EO-I to evaluate capacity of new generation of Landsat sensors for coastal/inland water studies. - Applied Earth Observations and Remote Sensing Journal. 6: 360-374.

[26] Pahlavan, N., Wei, J., Schaaf, B. C., Schott, R. J. (2014): Evaluating radiometric sensitivity of Landsat 8 over coastal / inland waters.- Geoscience and Remote Sensing Symposium (IGARSS), IEEE International, 13-18 July. Quebec City, QC, Canada. DOI: 10.1109/IGARSS.2014.6946695. 
[27] Pienitz, R., Vincent, W. F. (2000): Effect of climate change relative to ozone depletion on UV exposure in subarctic lakes. - Nature 404: 484-487.

[28] Proffitt, F. (2010): How clean are our rivers? https://www.niwa.co.nz/publications/wa/water-atmosphere-1-july-2010/how-clean-areour-rivers.

[29] Song, K. S., Li, L., Wang, Z. M., Liu, D. W., Zhang, B., Xu, J. P., Du, J., Li, L. H., Li, S., Wang, Y. D. (2012): Retrieval of total suspended matter (TSM) and chlorophyll- $a$ (Chla) concentration from remote-sensing data for drinking water resources. - Environmental Monitoring Assessment Journal 184: 1449-1470.

[30] Slonecker, E. T., Jones, D. K., Pellerin, B. A. (2016): The new Landsat 8 potential for remote sensing of colored dissolved organic matter (CDOM). - Marine Pollution Bulletin 107(2): 518-527.

[31] Tranvik, L. J. (1990): Bacterioplankton growth on fractions of dissolved organic carbon of different molecular weights from humic and clear waters. - Applied and Environmental Microbiology Journal 56(6): 1672-1677.

[32] Verburg, P. (2011): Disentangling effects of eutrophication and CDOM on visual water clarity in Lake Brunner: preliminary data and methods. - NIWA Client Report HAM2011-009. Prepared for West Coast Regional Council.

[33] Vincent, K. R., Qin, X., McKay, R. M., Miner, J., Czajkowski, K., Savino, J. (2004): Phycocyanin detection from LANDSAT TM data for mapping cyanobacterial blooms in Lake Erie. - Remote Sensing and Environment Journal 89(3): 381-392.

[34] Zhang, Y., Zhou, Y., Shi, K., Qin, B. (2018): Optical properties and composition changes in chromophoric dissolved organic matter along trophic gradients: Implications for monitoring and assessing lake eutrophication. - Water Research 131: 255-263.

[35] Zhou, W., Wang, S., Zhou, Y., Troy, A. (2006): Mapping the concentrations of total suspended matter in lake Taihu, China, using Landsat-8 TM data. - International Journal of Remote Sensing 27: 1177-1191. 